Marquette University

e-Publications@Marquette

College of Nursing Faculty Research and

Publications

Nursing, College of

4-1-2011

Fit Into College: A Program to Improve Physical Activity and Dietary Intake Lifestyles Among College Students

\author{
Robert V. Topp \\ Marquette University, robert.topp@marquette.edu \\ Jean S. Edward \\ University of Louisville \\ S. Lee Ridner \\ University of Louisville \\ Dean E. Jacks \\ University of Louisville \\ Karen Newton \\ University of Louisville \\ See next page for additional authors
}

Published version. Recreational Sports Journal, Vol. 35, No. 1 (April 2011): 69-78. DOI. (C) 2010

Human Kinetics, Inc. Used with permission. 
Authors

Robert V. Topp, Jean S. Edward, S. Lee Ridner, Dean E. Jacks, Karen Newton, Patricia Keiffner, Deborah Woodall, and Kathleen P. Conte 


\title{
Fit Into College: A Program to Improve Physical Activity and Dietary Intake Lifestyles Among College Students
}

\author{
Robert Topp, Jean S. Edward, S. Lee Ridner, Dean E. Jacks, \\ Karen Newton, Patricia Keiffner, Deborah Woodall, \\ and Kathleen P. Conte
}

The purpose of this study was to determine whether a 10-week program could improve physical activity, physical fitness, body weight, dietary intake, and perceptions of exercise and diet among college 30 healthy college freshmen. Outcomes were measured at baseline, and following the 10 -week program. The weekly sessions incorporated constructs of the Transtheoretical Model of Health Behavior Change and were administered by fitness interns who were junior or senior college students enrolled in health-related majors. The participants presented with low physical activity, physical fitness, and poor dietary intake, and $50 \%$ were overweight/obese (BMI $>25$ ). Participants demonstrated gains in their physical fitness and their perceived benefits to engaging in exercise and decreased their perceived barriers to engaging in exercise and a healthy diet. College freshmen presented with low levels of physical activity, poor dietary intake, and excess body weight. A peer-administered program can improve these measures and favorably change perceptions of exercise and diet.

Keywords: freshmen, obesity, exercise, diet, health

The transition from high school to college is a unique time in an adolescent's life. In addition to concerns related to academic majors, housing, and forming new social networks, students begin exploring different lifestyles including varied levels of physical activity (Calfas et al., 2000) and dietary habits. Physical activity patterns adopted during adolescence are strong predictors of physical activity patterns observed in adulthood (Malina, 2001). Lifestyles which include excess dietary intake relative to caloric expenditure from physical activity results in weight gain and overweight or obese children, who are 6.2 times more likely to grow

Topp is Shirley B. Powers Chair for Health Systems Research, School of Nursing, University of Louisville, Louisville, KY. Edward is a Doctoral Student with the School of Nursing, University of Louisville. Ridner is an Assistant Professor with the School of Nursing, University of Louisville. Jacks is an Assistant Professor with the Dept. of Health and Sports Sciences, University of Louisville. Newton is Director of the Dept. of Health Promotion and Education, University of Louisville. Keiffner is with the Dept. of Health and Sport Sciences, University of Louisville. Woodall is Assistant Director of the Fitness Programs \& HSC Fitness Center, University of Louisville. Conte is Associate Director, Health Promotion and Education, University of Louisville. 
into overweight or obese adults (Herman, Craig, Gauvin, \& Katzmarzyk, 2008). Previous research has found that during the first year of college most freshmen gain approximately .73 pounds per month (Hovell, Mewborn, Randle, \& FowlerJohnson, 1985) to 4.2 pounds over 12 weeks, (Levitsky, Halbmaier, \& Mrdjenovic, 2004) to 2.5 pounds over a semester (Megel, Wade, Hawkins, Norton et al., 1994). Thus, weight gain during the freshman year in college may range from 7.5 to 18.2 lbs. Previous research has predominantly looked at female samples only (Hodge, Jackson, \& Sullivan, 1993; Hovell et al., 1985; Megel et al., 1994) although some have presented results from mixed samples of men and women, with all samples of college age freshmen observed to gain weight during their freshman year (Graham \& Jones, 2002; Levitsky et al., 2004).

Few studies have attempted to impact the problem of weight gain among college students. Project GRAD involved evaluating the impact of cognitive-behavioral or knowledge-oriented course among senior college students on their physical activity during the two years following graduation (Sallis et al., 1999). Before graduation the cognitive-behavioral program resulted in increased physical activity including leisure time activity, flexibility, and strength training among females in the study. The program had no impact on males before or following graduation.

Weight gain is a multifactorial issue among college students and is an emerging problem. Some previous programs have focused on dietary intake while others have explored physical activity programs with limited success. This project addressed some limitations of prior studies and developed a theoretical based program delivered by peers of the participants. The purpose of this Fit Into College (FIC) program was to determine if an interdisciplinary, theoretically based 10 -week program could impact physical activity, physical fitness, body weight, dietary intake, and perceptions of exercise and dietary intake among college students at a major university.

\section{Theoretical Framework}

The Transtheoretical Model (TTM) of health behavior change provided the theoretical framework for developing the program used in this study. The TTM has been applied to numerous health behaviors, including smoking cessation, physical activity, and dietary practices (van Leer, Hapner, \& Connor, 2008). The stages of behavioral change in the TTM include precontemplation, contemplation, preparation, action, and maintenance. Each week of the 10-week program focused on cognitive and behavioral components designed to progress the participants along the TTM continuum of behavioral change to increase their physical activity and to increase their dietary intake of fruits and vegetables (Prochaska \& Velicer, 1997). Interventions targeted at changing cognitive components were designed to move subjects through the stages of precontemplation, contemplation, and preparation, Behavioral interventions were targeted to progress subjects through the phases of preparation, action, and maintenance (see Table 1).

\section{Methods}

Data were collected from a single group of participants before and following their participation in the 10-week program. The program involved 10 different sessions based upon the TTM. These weekly sessions were approximately $30 \mathrm{~min}$ long and focused 


\section{Table 1 Weekly Intervention Sessions for Fit Into College (FIC) Program}

\begin{tabular}{l|ll}
\hline Week & Weekly session title & Cognitive (C) \& Behavioral (B) objective for the week \\
\hline 1 & $\begin{array}{l}\text { Introduction /What is } \\
\text { My Fitness Level }\end{array}$ & $\begin{array}{l}\text { C: To raise the participant's awareness of their fitness level com- } \\
\text { pared with normal levels for their age and gender based upon their } \\
\text { initial fitness testing. }\end{array}$
\end{tabular}

2 Meet the Equipment at the Gym

B: Develop short term and long term fitness goals with their individual fitness intern.

$3 \quad$ Caloric or nutrient density

Fieldtrip to the Grocery

Vending Machine Dining and Basic Pantry
C: Increase the perceived physical, emotional, social benefits of exercise. To decrease barriers to going to the university gym including embarrassment or unfamiliarity with the equipment. Increase social support involved with going to the university gym

B: Tour the university gym, develop a personalized exercise prescription and complete at least one session of their exercise prescription with their fitness intern. List the benefits and barriers of regular exercise.

C: Increase understanding of two key concepts for thinking critically about food choices: nutrient density and caloric density. Increase knowledge of foods and beverages that meet these conceptual guidelines. Increase self-efficacy about making smart food choices. Shift thinking away from "diet" to vitality.

B: Sort various examples of food and beverages into categories: nutrient dense, calorically dense, or both. Eat examples of tasty nutrient dense foods and state whether this food will be selected in the near future.

C: Increase self-efficacy knowledge in using a full service grocery store: Location of the store, how the store is arranged (fruits, vegetables and high fiber snacks) and identifies various methods of transportation to and from the grocery store. Understand how to read and use a grocery coupon circular.

B: Review a coupon circular with the fitness intern and plan a single day of "shelf stable" food (B, L D \& S) which includes $>2$ serving of milk, 5-6 servings of fruit/vegetables at a cost less than $\$ 15$. Meet and tour the local grocery store with the fitness intern and identify the location of various foods identified in the single day food plan. Identify a high fiber snack they would actually eat. Identify one new fruit/vegetable/dairy/high fiber snack they have never eaten but would consider eating.

C: Increase awareness of the nutritional content (calories, fat \& sugar) of their favorite foods and other foods available in the campus convenience store and vending machines. Understand the importance of having a pantry stocked with basic food items and knowing how to cook simple meals from those items, supplemented with fresh produce and dairy.

B: With the assistance of their fitness intern select low calorie, low fat and/or low sugar foods in the campus convenience store and vending machines. Use the coupon for Basic Pantry kit to acquire recipe and foods from the Basic Pantry section of the on-campus convenience store and then use the recipe and ingredients to prepare a pasta meal, including fresh vegetables. 
Table 1 (continued)

\section{Week Weekly session title Cognitive (C) \& Behavioral (B) objective for the week}

$6 \quad$ Maintaining

Motivation

$\mathrm{C}$ : Identify benefits and barriers to maintaining a lifestyle of regular exercise (time commitment, convenience, sleep, psychiatric symptoms, stress, concentration and study skills, health, etc).

B: Develop a contingency plan to maintain regular exercise (rain, unexpected closing, and travel). Identify 3 methods to maintain regular exercise (social support, contracting, setting goals publically) or to minimize the barriers to regular exercise.

$7 \quad$ Navigating the Dining Services Food Court

$\mathrm{C}$ : Increase knowledge of nutrient dense food choices on campus, shift attitudes toward looking for new food options, increase self efficacy to make healthier choices and reduce barriers to knowledge of options.

$\mathrm{B}$ : Use the guidelines presented in educational sessions to make nutrient dense food choices in the dining commons and report to fitness intern.

$8 \quad$ Residence Hall Exercise

$\mathrm{C}$ : Be aware that you do not have to go to the university gym to get a good workout. Tools and resources were given to complete a workout at home or outdoors.

B: Participate with the fitness intern in a single session of resistance training exercises outside of the gym. Participatory demonstrations were given at the weekly session by the fitness intern.

9 Cooking School: Residence Hall Chef

C: Decrease the barriers to cooking in residence hall kitchens. Increase confidence to prepare simple meals using resources in residence hall kitchen.

B: Observe student intern prepare a simple dish and taste the result. Plan and cook a simple and nutrient dense meal in the residence hall kitchen using healthy food choices.

10 Fit for Life

$\mathrm{C}$ : Evaluate the outcomes of changes in exercise and diet which assist your overall understanding and motivation for participating in a fitness/nutrition program. What can help you plan activities/ eating habits in a way that makes you more likely to stick with the program in the long run?

B: Develop a plan for maintaining exercise changes: What classes can I take during my free times during the day? How much time will this activity take? Despite good intentions and high level of motivation when starting a new activity, if it is not convenient for your existing lifestyle you will have a hard time sticking with it. Look for activities, facilities, and work out times that make sense in your schedule. If that's not possible rearrange your current schedule to make a permanent place in your daily and weekly schedule for exercise. 
on two aspects of behavioral change: the participant's cognitive structure (knowledge, attitudes, perceptions, and beliefs) and the participant's behavior regarding their physical activity and dietary intake. Table 1 provides an overview of these sessions.

To reinforce the content of the weekly sessions each participant was paired with a "fitness intern" over the 10-week duration of the program. These fitness interns were junior or senior college students enrolled in either Exercise Science or Health Education programs at the university. Fitness interns conducted the weekly sessions under the supervision of the project staff. They also met individually with their assigned freshman participants at least one time per week outside of the formal session to review the content of the sessions and achieve their weekly cognitive and behavioral objectives for the week. Employing junior and senior students as fitness interns were done for several reasons. Due to the fitness interns' understanding and communication skills with the freshman participants they were assumed to be effective health advisors, a trusted source of health information, and able to effectively impact health-related attitudes, beliefs, and behaviors (Baker et al., 1997; Fleury, Keller, Perez, \& Lee, 2009). Fitness interns also served as role models for their peers and help in enhancing the self-efficacy of the participants. Finally, as a result of their course work and knowledge of fitness and diet the junior and senior students were in a unique position to minimize the barriers and enhance the benefits of healthy behaviors.

\section{Sample}

A sample of 40 incoming freshmen who resided in the residence halls at a Midwestern university were recruited during freshmen orientation week 2009 to participate in the study. Participants included in the program were required to be English-speaking, enrolled full time as a freshman, live in the residence halls, be able to make a 10 -week commitment to participating in the program and not have a history of cardiovascular disease or any other physical condition that would prohibit continuous exercise at moderate intensity. Before data collection all participants signed an informed consent which was approved by the University of Louisville Institutional Review Board (IRB).

\section{Outcome Measures}

Demographic information was obtained at baseline. Physical activity, physical fitness, body weight, dietary intake, and perceptions of exercise and dietary intake were obtained before and following the 10-week program.

Levels of physical activity were measured using the International Physical Activity Questionnaire (IPAQ). The IPAQ measures the total number of minutes and days per week the participant engages in vigorous to moderate physical activity, walking, and sitting. Physical fitness was measured using assessment tools recommended by the President's Challenge Adult Fitness Test, which focuses on aerobic fitness, muscular strength, flexibility, and body composition. These areas were measured using resting heart rate and total number of sit ups and pushups performed in one minute. Body weight was measured using a regular weighing scale and height measurements were conducted using a stadiometer, which was later combined to calculate Body Mass Index (BMI) of participants. 
Maximum oxygen consumption $\left(\mathrm{VO}_{2 \max }\right)$ was estimated from heart rate response while the participant completed a 3 -min step test protocol. This step test protocol required the individual to step up and down on a 12-inch bench at a rate of 24 steps per minute for $3 \mathrm{~min}$. A Polar heart rate monitor (Polar Electro, Finland) was employed to continuously monitor the heart rate of the participant during the test. Heart rate was recorded throughout the test and immediately upon cessation of the test, at one, and two minutes posttest. In similar studies of children, other researchers (Yin et al., 2005) have used this test, which has been shown to be responsive to changes in cardiovascular fitness resulting from increases in physical activity. The individual's heart rate response during this assessment was then entered into a prediction equation developed by Jacks and colleagues (2008) to estimate $\mathrm{VO}_{2 \max }$. This method of estimating $\mathrm{VO}_{2 \max }$ has been reported to demonstrate a high correlation with direct measurements of $\mathrm{VO}_{2 \max }\left(R^{2}=.78\right)$ (Jacks, Moore, Topp, \& Bibeau, 2008).

During the two points of data collection each participant completed a 24-hour diet recall interview with a graduate research assistant. Participants were asked to recall their dietary intake in the past $24 \mathrm{hr}$. These records were coded into Nutritionist Pro's computerized diet analysis database to calculate each participant's daily consumption of calories, sugar, salt, and fiber. This nutrient analysis software program provides nutrient data for more than 35,000 foods and ingredients, including brand names and fast foods, yielding accurate nutritional intake calculations.

Perceptions of exercise and dietary intake behavior were assessed using two separate decisional balance scales. These scales measured the cognitive perceptions associated with regular exercise and fruit and vegetable intake behaviors. The regular exercise decisional balance measure has been tested with a group of adolescents and found to be a valid measure (Nigg \& Courneya, 1998). As the adolescents progressed through the stages of change, scores on the measure were statistically different on the benefits and barriers to regular exercise. In the later stages of change, the benefits were much higher than the barriers to engaging in regular exercise. To examine the cognitive changes associated with dietary intake of fruits and vegetables, a scale developed by Henry and colleagues (2006) was used. As with the other scales, individuals at varying stages of change were observed to have statistically different scores on the perceived benefits and barriers to consuming fruits and vegetables.

\section{Results}

Over 80 incoming freshman contacted the program staff and expressed an interest in participating in the program during freshman orientation 2009 . The first 40 individuals, who contacted the program staff were recruited into the program, signed informed consents and completed pre program data collection measures. Thirty $(75 \%)$ individuals completed the entire FIC program including the post testing following the 10-week program. All of these individuals resided in the university's residence halls, $75 \%$ were female, and $57 \%$ of them participated in a high school sport. Fifty percent of the participants were classified as overweight or obese (BMI $>25$ ). Table 2 indicates preprogram and postprogram physical activity, physical fitness, body weight, dietary intake, and perceptions of regular exercise and fruit and vegetable intake of the freshman sample. This table also presents recommended 


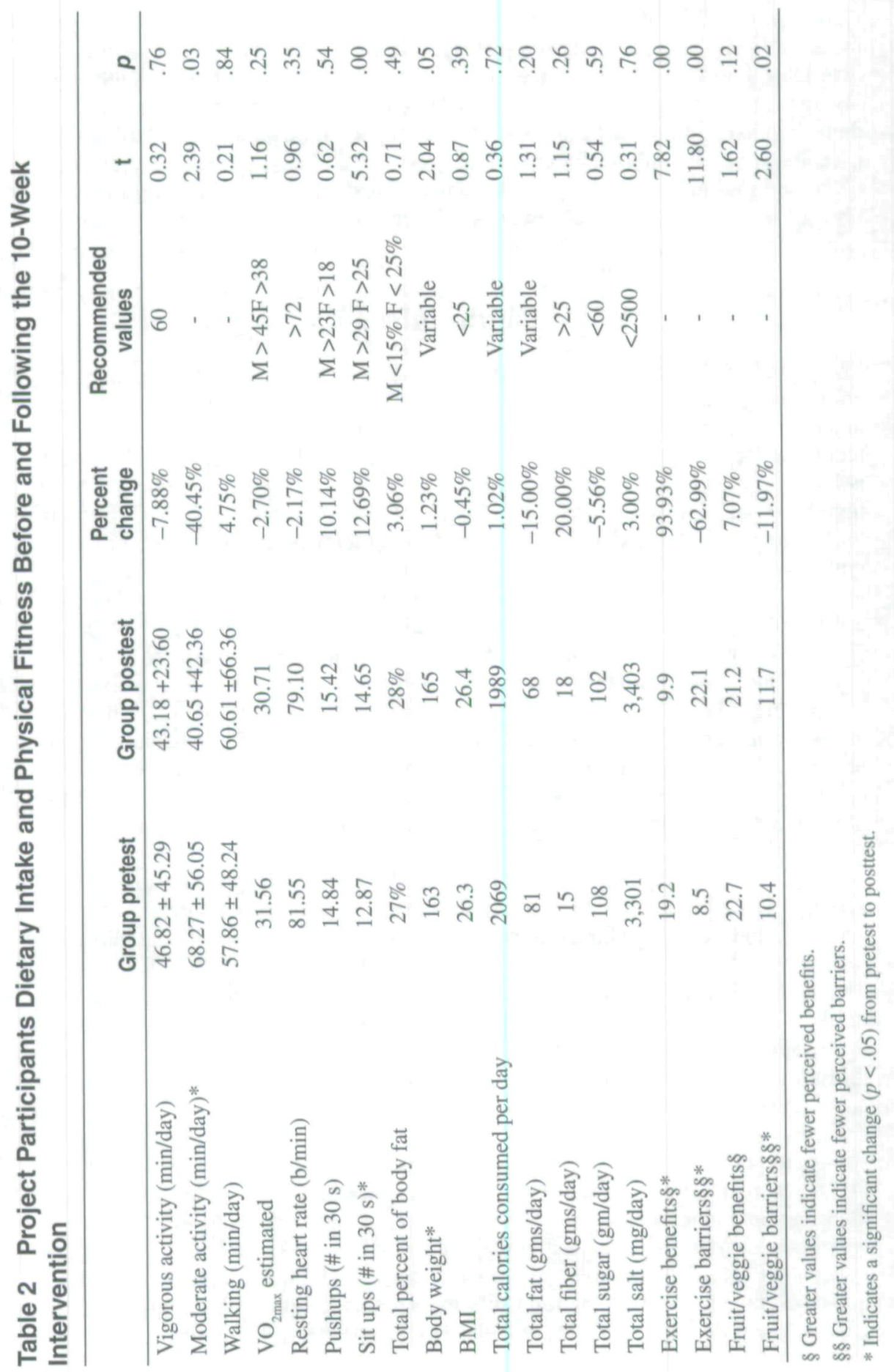


values for these variables. Repeated measures univariate analyses were conducted to determine if the subjects significantly $(p<.05)$ changed on any of these variables over the duration of the project. A majority of the outcome variables indicated a favorable trend toward changes in physical activity, physical fitness, body weight, dietary intake, and perceptions of regular exercise and fruit and vegetable intake (See Table 2). The only significant changes in these outcome variables included a decrease in minutes spent in moderate activity, and an increase in sit-ups. Perceptions of the benefits of regular exercise significantly increased while the barriers to regular exercise and consuming fruits and vegetables significantly decreased.

\section{Discussion}

The pretest findings of the freshman participants validate the emerging problem of overweight and obesity among the incoming freshman class at this Midwestern university. Percentages of body fat, BMI, and body weight all appear in excess of recommended values among the incoming freshmen. This excessive body weight is likely related to low levels of vigorous physical activity and high durations of time spent being inactive or sitting. Both before and following the FIC program the participants averaged approximately $70 \%$ of their activity as inactive or sitting with less than 50 min per day spent in vigorous physical activity. This inactivity appears to result in low levels of physical fitness as evidenced by the low levels of estimated $\mathrm{VO}_{2 \max }$, high resting heart rates and below average abilities to complete sit ups and pushups. Compounding this problem is the poor dietary intake exhibited by incoming freshmen. During both the pretest and posttest it was observed that freshmen participants consumed below the recommended amount of fiber and excessive amounts of refined sugar and sodium. Before the program the participants' perceived benefits of exercise were approximately half their perceived barriers to engaging in exercise among the sample. Similarly, the samples perceived benefits of fruit and vegetable intake at baseline appeared to be approximately half that of the perceived barriers to fruit and vegetable intake.

Although not statistically significant the effect of the FIC program on physical activity, physical fitness, body weight, dietary intake, and perceptions of exercise and fruit and vegetable intake appeared promising. A majority of the variables demonstrated a trend in the hypothesized direction as a result of the FIC program. They consumed fewer calories, fat, and refined sugar while increasing their intake of fiber. The FIC sample slightly decreased their vigorous activity and duration of time spent sitting. Percent body fat, body weight, and BMI increased slightly over the duration of the program. Previous investigators have observed college freshmen gain an average of 7.5 to $18.2 \mathrm{lbs}$ in their first year of college (Hovell et al., 1985; Levitsky et al., 2004; Megel et al., 1994).The current sample was observed to gain approximately half the amount of weight gained by freshmen in previous studies. Finally, perceptions of regular exercise as a result of the FIC program changed favorably and significantly $(p<.05)$. The sample nearly doubled their perceived benefits of exercise while reducing their perceived barriers to engaging in exercise by greater than half. The participants also expressed a slight non significant increase in the perceived benefits of eating fruits and vegetables while expressing a significant $(p<.05)$ decrease in their perceived barriers to eating fruits and vegetables. 


\section{Implications}

The findings that students are entering the university in poor physical condition and consuming a poor diet is consistent with the growing problem of obesity observed across the population. The FIC Program which includes weekly intervention sessions and fitness interns can favorably impact physical activity, physical fitness, body weight, and dietary intake of the participants in this sample. Although it should be noted that the use of this convenience sample is a limitation of this study and results cannot be generalized to all students entering the university, further studies using larger random samples over long periods of time will address this issue. Future studies in this area may also examine the impact of the intervention over a longer duration beyond six months to address maintenance of the desired health behavior changes as recommended by the TTM. These findings provide rational for developing similar programs that take advantage of resources available within most universities which will address the problem of obesity of the students. Using this program as a guide, directors of recreational and sports programs within universities can develop similar programs for students which incorporate internships by upper-class students who have the knowledge to facilitate under classmen to adopt physical activity and dietary patterns that promote healthier lifestyles.

\section{References}

American College Health Association. (2008). American College Health AssociationNational College Health Assessment spring 2007 reference group data report (abridged). Journal of American College Health, 56(5), 469-479.

Baker, E.A., Bouldin, N., Durham, M., Lowell, M.E., Gonzalez, M., Jodaitis, N., et al. (1997). The Latino Health Advocacy Program: a collaborative lay health advisor approach. Health Education \& Behavior, 24(4), 495-509.

Calfas, K.J., Sallis, J.F., Nichols, J.F., Sarkin, J.A., Johnson, M.F., Caparosa, S., et al. (2000). Project GRAD: two-year outcomes of a randomized controlled physical activity intervention among young adults. Graduate Ready for Activity Daily. American Journal of Preventive Medicine, 18(1), 28-37.

Centers for Disease Control and Prevention. (1997). Youth Risk Behavior Surveillance: National College Health Risk Behavior Survey-United States, 1995. Morbidity \& Mortality Weekly Report. MMWR. CDC Surveillance Summaries, 46(6), 1-56.

Fleury, J., Keller, C., Perez, A., \& Lee, S.M. (2009). The role of lay health advisors in cardiovascular risk reduction: a review. American Journal of Community Psychology, 44(1-2), 28-42.

Graham, M.A., \& Jones, A.L. (2002). Freshman 15: valid theory or harmful myth? Journal of American College Health, 50(4), 171-173.

Henry, H., Reimer, K., Smith, C., \& Reicks, M. (2006). Associations of decisional balance, processes of change, and self-efficacy with stages of change for increased fruit and vegetable intake among low-income, African-American mothers. Journal of the American Dietetic Association, 106(6), 841-849.

Herman, K.M., Craig, C.L., Gauvin, L., \& Katzmarzyk, P.T. (2009). Tracking of obesity and physical activity from childhood to adulthood: The Physical Activity Longitudinal Study. International Journal of Pediatric Obesity, 4, 281-288.

Hodge, C.N., Jackson, L.A., \& Sullivan, L.A. (1993). The "freshman 15": Facts and fantasies about weight gain in college women. Psychology of Women Quarterly, 17(1), 119-126.Hovell, M.F., Mewborn, C.R., Randle, Y., \& Fowler-Johnson, S. (1985). Risk 
of excess weight gain in university women: a three-year community controlled analysis. [Comparative Study]. Addictive Behaviors, 10(1), 15-28.

Jacks, D., Moore, J., Topp, R., \& Bibeau, W. (2008). Prediction of VO2 peak using a submaximal bench step test in children. Medicine and Science in Sports and Exercise, 40(S418),

Levitsky, D.A., Halbmaier, C.A., \& Mrdjenovic, G. (2004). The freshman weight gain: a model for the study of the epidemic of obesity. International Journal of Obesity \& Related Metabolic Disorders: Journal of the International Association for the Study of Obesity, 28(11), 1435-1442.

Louisville, University of (2008). Health risk appraisal. Louisville, KY: University of Louisville Campus Health.

Malina, R.M. (2001). Physical activity and fitness: pathways from childhood to adulthood. American Journal of Human Biology, 13(2), 162-172.

Megel, M.E., Wade, F., Hawkins, P., Norton, J., et al. (1994). Health promotion, self-esteem, and weight among female college freshmen. Health Values: The Journal of Health Behavior. Education \& Promotion, 18(4), 10-19.

Nigg, C.R., \& Courneya, K.S. (1998). Transtheoretical Model: examining adolescent exercise behavior. The Journal of Adolescent Health, 22(3), 214-224.

Prochaska, J.O., \& Velicer, W.F. (1997). The transtheoretical model of health behavior change. American Journal of Health Promotion, 12(1), 38-48.

Sallis, J.F., Calfas, K.J., Nichols, J.F., Sarkin, J.A., Johnson, M.F., Caparosa, S., et al. (1999). Evaluation of a university course to promote physical activity: project GRAD. Research Quarterly for Exercise and Sport, 70(1), 1-10.

van Leer, E., Hapner, E.R., \& Connor, N.P. (2008). Transtheoretical model of health behavior change applied to voice therapy. Journal of Voice, 22(6), 688-698.

Yin, Z., Hanes, J., Jr., Moore, J.B., Humbles, P., Barbeau, P., \& Gutin, B. (2005). An afterschool physical activity program for obesity prevention in children: the Medical College of Georgia FitKid Project. Evaluation \& the Health Professions, 28(1), 67-89. 
Copyright of Recreational Sports Journal is the property of Human Kinetics Publishers, Inc. and its content may not be copied or emailed to multiple sites or posted to a listserv without the copyright holder's express written permission. However, users may print, download, or email articles for individual use. 